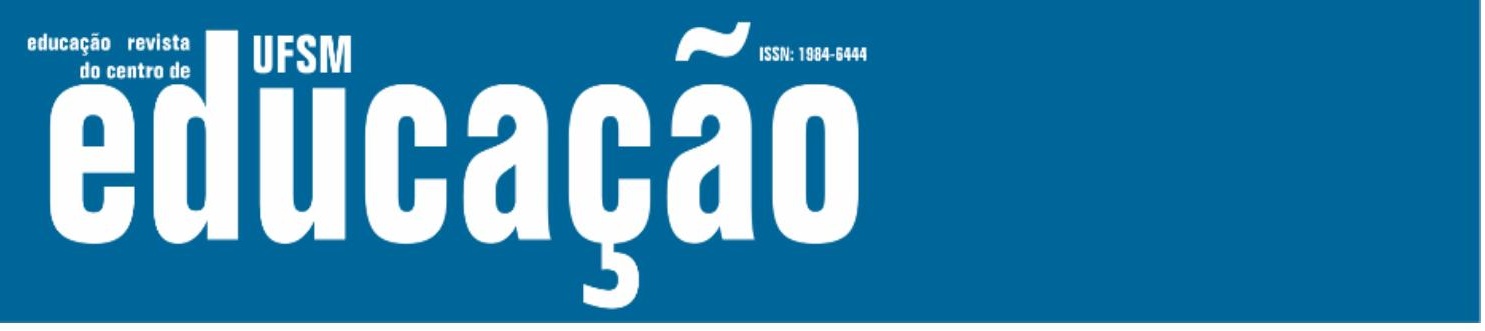

ISSN: 1984-6444 | http://dx.doi.org/10.5902/1984644433540

\title{
A Educação Ambiental e a Prática Pedagógica: um diálogo necessário
}

\author{
Environmental Education and Pedagogical Practice: a necessary \\ dialogue
}

Chrizian Karoline Oliveira

Mestre na Pontifícia Universidade Católica do Paraná, Curitiba, Paraná, Brasil.

chriziankaroline@hotmail.com - https://orcid.org/0000-0002-6049-1601

Daniele Saheb

Professora doutora na Pontifícia Universidade Católica do Paraná, Curitiba, Paraná, Brasil. danisaheb@yahoo.com.br - https://orcid.org/0000-0003-1317-6622

Daniela Gureski Rodrigues

Doutoranda na Pontifícia Universidade Católica do Paraná, Curitiba, Paraná, Brasil. dany_gureski@yahoo.com.br - https://orcid.org/0000-0001-6144-0542

Recebido em 22 de abril de 2019

Aprovado em 30 de abril de 2019

Publicado em 29 de março de 2020

\section{RESUMO}

De acordo com as Diretrizes Curriculares Nacionais de Educação Ambiental (BRASIL, 2012), a Educação Ambiental deve estar presente no currículo do ensino formal, de modo contínuo, permanente e interdisciplinar. Com base nesta perspectiva, o presente trabalho teve como objetivo identificar a concepção de Educação Ambiental dos professores que atuam nessa temática, no âmbito do Projeto Equidade da Rede Municipal de Curitiba-PR. Buscou-se, ainda, compreender de que modo essa concepção reflete na prática pedagógica dos docentes envolvidos. Como proposta metodológica foi delimitado um instrumento de coleta de dados: o questionário, além disso, foram também realizadas a pesquisa bibliográfica e a análise documental. No que se refere ao questionário, este se deu por meio da técnica Delphi e foi aplicado aos professores da Prática de Educação Ambiental, de escolas que participam do Projeto Equidade. Os resultados apontaram para a necessidade de serem dados mais subsídios teóricos e metodológicos aos professores, para que possam promover aprendizagens mais significativas por meio das práticas em EA, ressaltando, assim, a relevância de se trabalhar com os problemas que afetam principalmente a região local, permitindo um envolvimento maior por parte do professor, possibilitando reflexões imprescindíveis à temática ambiental, quer sejam culturais, sociais, econômicas, quer sejam políticas e históricas.

Palavras-chave: Educação Ambiental; Prática Educativa; Ensino Fundamental. 


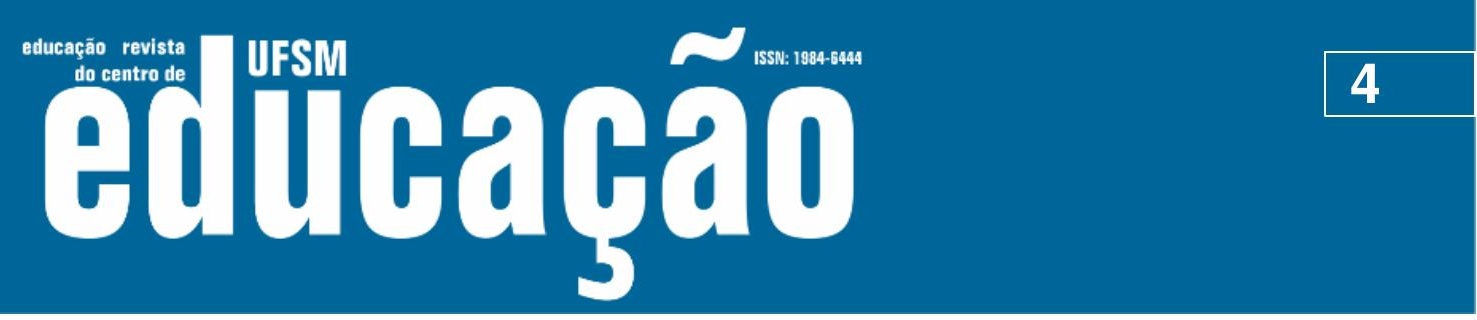

ISSN: 1984-6444 | http://dx.doi.org/10.5902/1984644433540

O saber ambiental problematiza o conhecimento fragmentado em disciplinas e a administração setorial do desenvolvimento, para constituir um campo de conhecimentos teóricos e práticos orientado, para constituir um campo de conhecimento teórico e práticos orientado para a rearticulação das relações sociedade-natureza. Este conhecimento não se esgota na extensão dos paradigmas da ecologia para compreender a dinâmica dos processos socioambientais, nem se limita a um componente ecológico nos paradigmas atuais do conhecimento (LEFF, 2015 p. 145)

Nesse contexto, faz-se necessário uma postura crítica por parte dos profissionais que, associada a uma prática docente pertinente, contribuirá para a formação de cidadãos mais conscientes, tanto a médio, como em longo prazo. Nos anos iniciais do Ensino Fundamental, essa ação crítica se torna prometedora, pois nesta fase os alunos estão em processo de descoberta e de transformação. Loureiro, Layrargues e Castro, apontam que a:

Educação Ambiental é uma prática dialogada com a questão ambiental. E no
sensu comum, essa prática visa à mudança de valores, atitudes e
comportamentos para o estabelecimento de uma outra relação entre o ser
humano e a natureza, que deixe de ser instrumental e utilitarista, para se
tornar harmoniosa e respeitadora dos limites ecológicos. Uma relação em que
agora a natureza não seja mais compreendida apenas como um 'recurso
natural' passível de apropriação a qualquer custo para usufruto humano.
(LOUREIRO; LAYRARGUES; CASTRO, 2009, p. 25-26)

Com base nessa perspectiva, é preciso introduzir a questão ambiental de forma sensibilizadora, oportunizando a percepção dos alunos em relação à necessidade do cuidado e respeito voltados para um compromisso social com o ambiente. Nesse âmbito, Loureiro, Layrargues e Castro (2009, p. 27) destacam que "fazer a Educação Ambiental como compromisso social significa reestruturar a compreensão de Educação Ambiental, para estabelecer a conexão, entre justiça ambiental, desigualdade e transformação social [...]", ou seja, uma educação para a cidadania, uma educação transformadora que permita observar com clareza as questões, tanto sociais, quanto ambientais.

A proposta de Educação Ambiental deve estar alinhada a uma natureza interdisciplinar e multidimensional, envolvendo aspectos ambientais, sociais, políticos, econômicos e culturais.

O programa Mais Educação, principal programa do Governo Federal voltado para a implementação da Educação em tempo Integral na escola básica brasileira, 


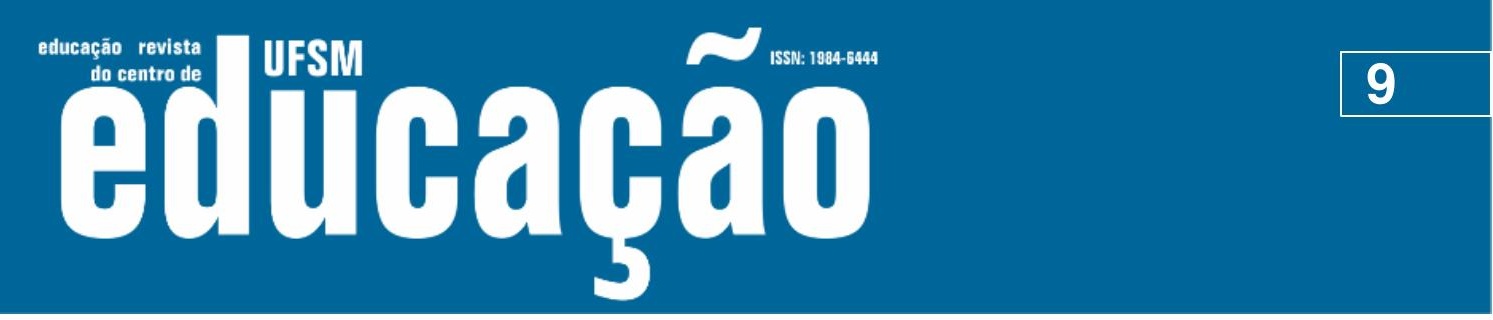

ISSN: 1984-6444 | http://dx.doi.org/10.5902/1984644433540

conhecimentos científicos e saberes populares; é a prática na qual o ser (individual e coletivo) se forja no saber" (LEFF, 2010, p. 8).

Essa pedagogia ambiental "se fundamenta na fusão entre a pedagogia crítica e o pensamento da complexidade" (LEFF, 2010, p. 9), dando lugar à complexidade ambiental, a qual de acordo com Leff:

[...] é uma nova compreensão do mundo, incorporando o limite do conhecimento e a incompletude do ser. Implica saber que a incerteza, o caos e o risco são ao mesmo tempo efeito da aplicação do conhecimento que pretendia anulá-los, é condição intrínseca do ser e do saber. (LEFF, 2010, p.22)

Isso significa que a união é a possibilidade de contemplar e compreender a complexidade presente em um mundo que não é organizado e ordenado, mas sim, caótico, repleto de contradições, conflitos e desafios que, segundo Behrens e Ens (2015, p.31) "na realidade, busca aceitar uma mudança periódica de paradigma, uma transformação na maneira de pensar, de se relacionar e de agir para investigar e integrar novas perspectivas".

Se tal perspectiva complexa for voltada para desenvolver práticas educativas reflexivas e fundamentadas no saber ambiental, isso resultará em uma racionalidade ambiental. Conforme Loureiro, Layrargues e Castro:

Educação Ambiental é prática que dialoga com a questão ambiental. E no
senso comum, essa prática visa à mudança de valores, atitudes e
comportamentos para o estabelecimento de uma outra relação entre o ser
humano e a natureza, que deixe de ser instrucional e utilitarista, para se tornar
harmoniosa e respeitadora dos limites ecológicos. Uma relação em que agora
a natureza não seja mais comprometida apenas como um 'recurso natural'
passível de apropriação a qualquer custo para usufruto humano.
(LOUREIRO; LAYRARGUES; CASTRO 2009, p. 26)

Para que essa mudança de pensamento, e, por conseguinte, de práticas pedagógicas, seja possível, é necessário que o professor (a) compreenda a si mesmo, aceitando e percebendo que as incertezas e os erros fazem parte de um processo reflexivo de autoformação tanto pessoal, quanto profissional, propiciando um conhecimento que liberta, promove momentos criativos, produtivos, em um esforço planejado, sistemático e paralelo, ao mesmo tempo que articula, aspectos, ontológicos, epistemológicos, metodológicos e estratégicos. 


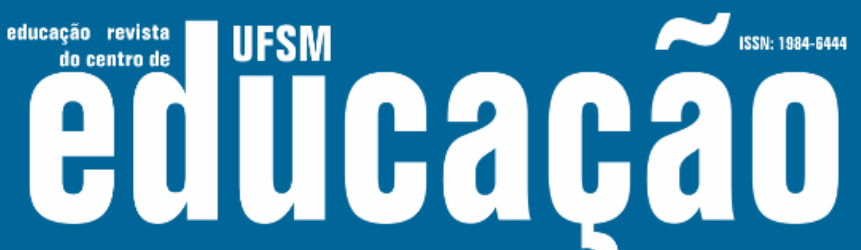

ISSN: 1984-6444 | http://dx.doi.org/10.5902/1984644433540

\section{Correntes da Educação Ambiental}

Entender e identificar os conceitos e concepções que possuímos possibilita uma reflexão ativa sobre o nosso agir tanto individual, quanto em um âmbito social, portanto "a análise das diferentes maneiras de conceber e praticar a EA contribui para que possamos identificar as que convergem com o contexto de pesquisa ou de intervenção, e escolher então as que poderão subsidiar a nossa própria prática" (SAHEB, 2013, p.15).

Sauvé (2005), a esse respeito, aponta que a Educação Ambiental pode ser compreendida de várias maneiras e, para tanto, categorizou tais compreensões em quinze correntes, "[...] a noção de correntes refere-se aqui, a uma maneira geral de conceber e praticar a educação ambiental". (SAUVÉ 2005 p. 17).

Para essa categorização, Sauvé (2005) utilizou os seguintes parâmetros:

Figura 1 - Parâmetros de organização

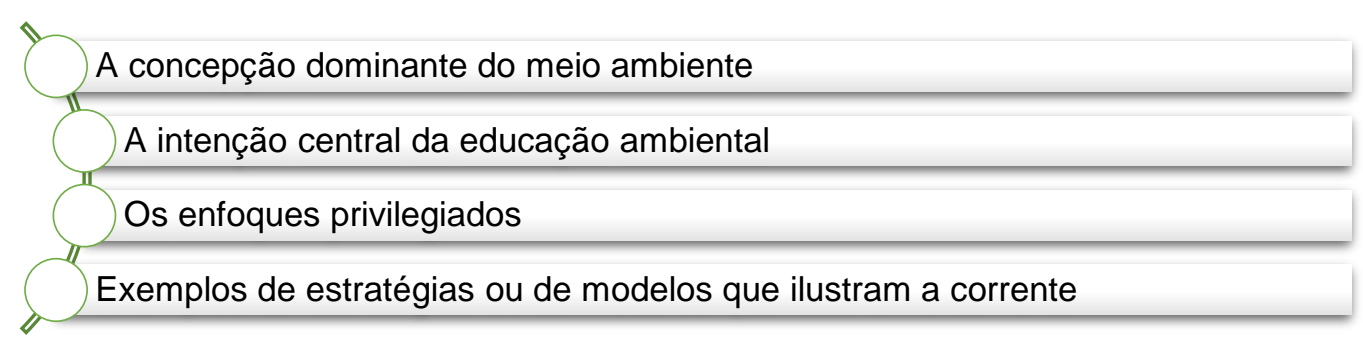

Fonte: Elaborada pelas autoras, baseada em Sauvé (2005)

Tais correntes foram divididas em dois grupos. O primeiro refere-se às correntes mais antigas, utilizadas com mais intensidade nas décadas de 1970 e 1980. Já o segundo grupo corresponde às correntes mais recentes da Educação Ambiental.

Serão apontadas, de forma breve, as principais características das correntes de Educação Ambiental a serem utilizadas como instrumentos para a reflexão e análise dos materiais coletados, a fim de identificar a concepção de Educação Ambiental dos professores dos anos iniciais do Ensino Fundamental, que atuam na Prática de Educação Ambiental no Projeto Equidade. 


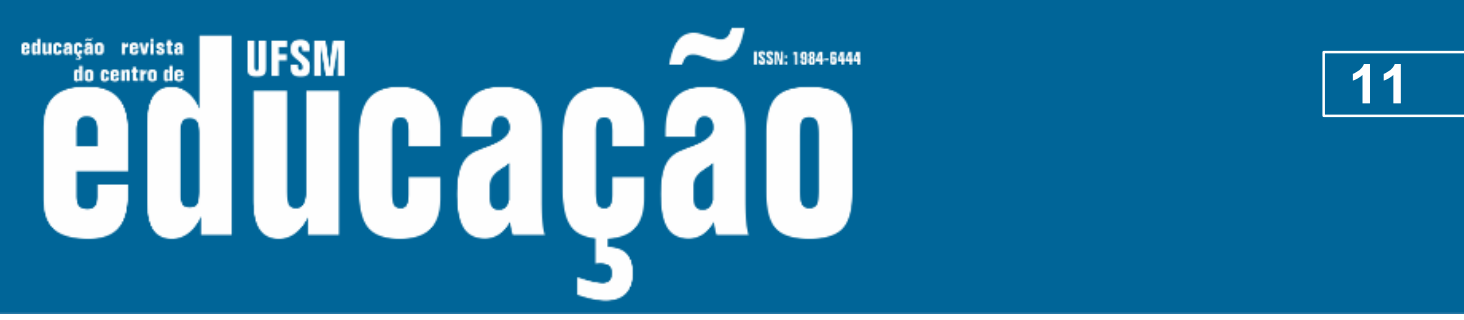

ISSN: 1984-6444 | http://dx.doi.org/10.5902/1984644433540

Figura 2 - Correntes mais recentes da Educação Ambiental

\begin{tabular}{|c|c|}
\hline CORRENTE HOLISTICA & $\begin{array}{l}\text { - Tem um enfoque na análise racional das realidades } \\
\text { ambientais e dos sujeitos nela envolvidos }\end{array}$ \\
\hline $\begin{array}{l}\text { CORRENTE } \\
\text { BIORREGIONALISTA }\end{array}$ & $\begin{array}{l}\text { - Tem como eixo estruturante os aspectos geográficos } \\
\text { (naturais e humanos) }\end{array}$ \\
\hline CORRENTE PRÁXICA & $\begin{array}{l}\text {-Ênfase na integração da reflexão com a ação, } \\
\text { apresentado um caráter de pesquisa-ação }\end{array}$ \\
\hline CORRENTE CRÍTICA SOCIAL & -Adota uma postura emancipadora e libertadora \\
\hline CORRENTE FEMINISTA & $\begin{array}{l}\text {-Tem seu início com os movimentos feministas, visando à } \\
\text { crítica social }\end{array}$ \\
\hline CORRENTE ETNOGRÁFICA & • Foco no caráter cultural da relação com o meio ambiente \\
\hline CORRENTE ECOEDUCAÇÃO & $\begin{array}{l}\text {-Tem como ponto central a parte educacional da } \\
\text { Educação Ambiental }\end{array}$ \\
\hline $\begin{array}{l}\text { CORRENTE DA } \\
\text { SUSTENTABILIDADE }\end{array}$ & $\begin{array}{l}\text {-Apoia-se nas recomendações da Agenda } 21 \text { e nos } \\
\text { programas propostos pela UNESCO }\end{array}$ \\
\hline
\end{tabular}

Fonte: Elaborada pelas autoras, baseada em Sauvé (2005).

Figura 3 - Correntes mais antigas de Educação Ambiental

\begin{tabular}{|c|c|}
\hline CORRENTE NATURALISTA & - Tem como eixo estruturante o contato com a natureza \\
\hline $\begin{array}{c}\text { CORIRIENIIE } \\
\text { CONSERVACIONISTA OU } \\
\text { RECURSISTA }\end{array}$ & - Centra-se na conservação dos recursos naturais \\
\hline CORRENTE RESOLUTIVA & -Estrutura-se na solução de problemas ambientais \\
\hline CORRENTE SISTÊMICA & $\begin{array}{l}\text { - Centra-se na análise dos componentes que integram um } \\
\text { sistema ambiental }\end{array}$ \\
\hline CORRENTE CIENTIIFICA & $\begin{array}{l}\text { - Tem como ênfase o rigor cientifico, centrando-se na } \\
\text { elaboração de hipóteses e na averiguação delas }\end{array}$ \\
\hline CORRENTE HUMANISTA & $\begin{array}{l}\text { - Compreende o meio como um meio de vida, com suas } \\
\text { dimensões sociais, culturais, politicas e históricas }\end{array}$ \\
\hline CORRENTE MORAL/ÉTICA & -Propõe o desenvolvimento de valores ambientais \\
\hline
\end{tabular}

Fonte: Elaborada pelas autoras, baseada em Sauvé (2005)

Educação | Santa Maria | v. 45 |2020

Disponível em: https://periodicos.ufsm.br/reveducacao 


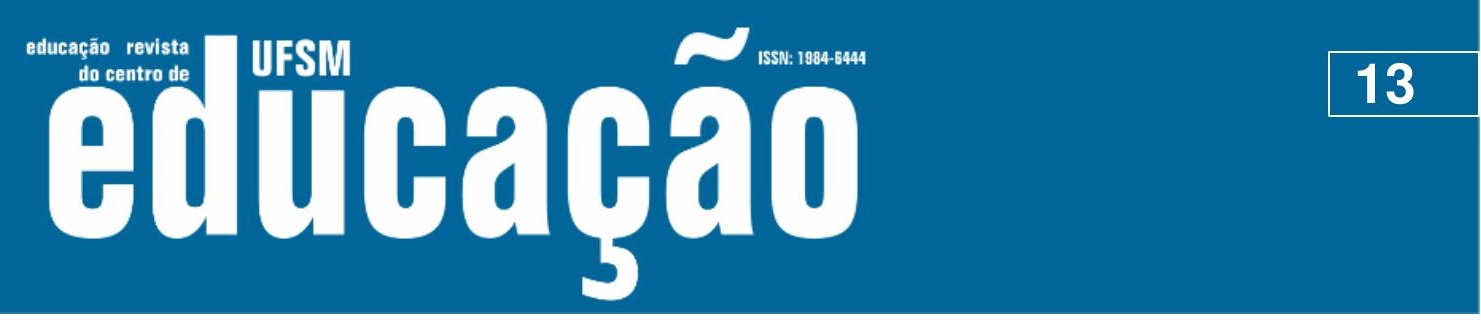

ISSN: 1984-6444 | http://dx.doi.org/10.5902/1984644433540

Conforme Antunes (2014, p.64), a técnica Delphi se constitui "como uma ferramenta útil no campo da pesquisa na área da educação, em temáticas como: planejamentos estratégicos; definição de competências e perfis profissionais; definição de conteúdo educacionais". Cada fase das respostas do questionário é chamada de rounds. A coleta de dados desta pesquisa se desenvolveu em dois rounds.

A primeira fase "é de exploração do tema, quando a contribuição individual adiciona informações sobre o que é pertinente ao debate" (ANTUNES, 2014, p. 65). As questões dessa primeira fase devem ser abertas para possibilitar que os participantes tenham ampla liberdade para responder. De acordo com Minayo (2014, p. 269):

Numa primeira fase, o pesquisador envia 0 instrumento (questionário ou roteiro) a um conjunto de especialistas. A partir das respostas, é feito outro instrumento que leva em conta as contribuições dos especialistas e, outra vez, Ihes e endereçado para que se pronunciem sobre seu grau de acordo com cada afirmação.

Após o contato com todas as escolas, e realizar as visitas naquelas que as permitiram, foi finalizada a primeira etapa da pesquisa com um total de 15 participações de professores das 37 escolas envolvidas no processo.

Quadro 1 - Perfil dos professores participantes da pesquisa

\begin{tabular}{|c|c|c|c|}
\hline Professor (a) & Sexo & Idade & $\begin{array}{c}\text { Experiência profissional na } \\
\text { Educação Básica }\end{array}$ \\
\hline P-1 & F & 46 anos & 03 anos \\
\hline P-2 & F & 31 anos & 05 anos \\
\hline P-3 & F & 44 anos & 10 anos \\
\hline P-4 & F & 31 anos & 10 anos \\
\hline P-5 & F & 38 anos & 12 anos \\
\hline P-6 & F & 43 anos & 23 anos \\
\hline P-7 & F & 40 anos & 17 anos \\
\hline P-8 & F & 48 anos & 17 anos \\
\hline P-10 & F & 48 anos & 20 anos \\
\hline P-11 & F & 48 anos & 17 anos \\
\hline P-12 & F & 55 anos & 15 anos \\
\hline P-13 & F & 48 anos & 20 anos \\
\hline P-14 & M & 44 anos & 19 anos \\
\hline P-15 & F & 47 anos & 5 anos \\
\hline
\end{tabular}

Fonte: as autoras (2017). 


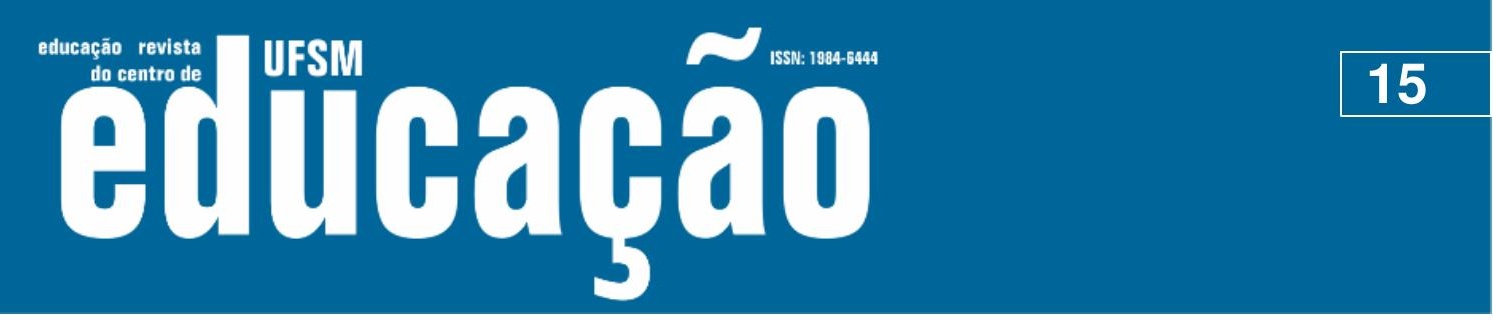

ISSN: 1984-6444 | http://dx.doi.org/10.5902/1984644433540

Nesta parte da pesquisa houve uma redução no número de participantes, de 15 para 09 professores. As justificativas apresentadas por alguns dos participantes foram as seguintes: mudança de área e excesso de atividades; falta de tempo decorrente do grande número de pesquisas realizadas na instituição em que atuava. Os demais participantes que desistiram, sem justificativa, não responderam às tentativas de contado, nem tampouco à pesquisa.

\section{Análise e Resultados}

\section{Educação Ambiental na Prática Pedagógica dos Professores}

Para compreender a importância e como a Educação Ambiental é desenvolvida na prática pedagógica, visto que é o reflexo de concepções, bem como dos ideais implícitos na postura e direcionamentos dos professores, estes foram questionados da seguinte maneira: Como a Educação Ambiental deve se desenvolver na escola? E por quê? Desse modo, análise que se segue irá apresentar a resposta deles ao questionamento supracitado.

Uma das concepções ressaltadas nas práticas educativas, propostas pelos professores, foram direcionamentos voltados à perspectiva naturalista de Educação Ambiental que, de acordo com Sauvé, consiste em:

[...] convidar as crianças (ou outros participantes) a vivenciarem experiências cognitivas e afetivas em um meio natural, explorando o enfoque experiencial, a pedagogia do jogo e o atrativo de se pôr em situações misteriosas ou mágicas, a fim de adquirir uma compreensão dos fenômenos ecológicos e desenvolver um vínculo com a natureza. (SAUVÉ, 2005, p. 19)

Tal perspectiva evidenciou-se da seguinte maneira:

Unindo a teoria à prática. Nas minhas aulas as crianças têm contato com animais, como passarinhos, uma tartaruguinha e um peixinho, algumas plantas ornamentais e umas medicinais. Aprendem os cuidados com os seres vivos e a importância do meio ambiente saudável. $(P-1)$.

Através de práticas. Ex: horta $(P-3)$.

Deve ser desenvolvida através de projetos, aulas práticas, pois as crianças aprendem mais com aulas lúdicas e prazerosas, exemplo: horta onde você pode explorar tipos de seres vivos (plantas/insetos), cuidados com o ambiente, plantas medicinais, vitaminas das verduras e legumes nela plantada. $(P-9)$. 


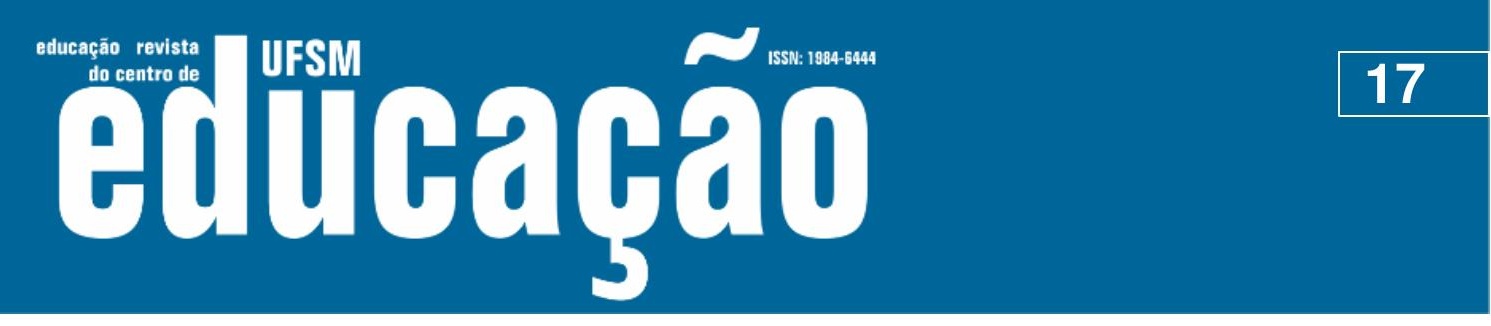

ISSN: 1984-6444 | http://dx.doi.org/10.5902/1984644433540

Guimarães (2014 p. 38), com base nessa ideia, tece uma consideração sobre as práticas ambientais, na qual "essa prática não se realiza sozinha, mas nas relações do ambiente escolar, na interação entre diferentes atores, conduzida por um sujeito, os educadores". Por essa razão, a motivação pela busca de novos conhecimentos e entendimentos é imprescindível para a realização das práticas ambientais.

Em consonância com os pressupostos apresentados anteriormente, voltados a uma Educação Ambiental crítica, foram apresentados direcionamentos orientados para as práticas ambientais nessa perspectiva, as quais se evidenciaram da seguinte forma:

\begin{abstract}
O trabalho com a prática deve ter como pressuposto uma visão ética de responsabilidade pessoal e social em relação ao meio ambiente e a um futuro sustentável, pensando em atividades que promovam a compreensão da rede de relações entre pessoas e organizações em seus ambientes naturais e contextos históricos, analisando os modelos de consumo baseados no crescimento e assumindo uma nova consciência de consumo. Para atender a essa especificidade de trabalho, é necessário que o planejamento das Práticas de Educação Ambiental contemple a reorganização e a otimização dos ambientes escolares, como, por exemplo, o espaço destinado horta escolar. Além disso, existem outros espaços no entorno da escola (mercados, igrejas, farmácias, padarias, entre outros) e outros locais da cidade (parques, museus, centros históricos, entre outros) que podem ser utilizados como territórios educativos contribuindo para $o$ enriquecimento dos encaminhamentos metodológicos das Práticas de Educação Ambiental. ( $P$ 7).

Acredito ser importante trabalhar primeiramente o Eu [...] quem eu sou como posso melhorar enquanto pessoa, o respeito ao próximo e outras questões de convívio. Passado esse momento ampliar a discussão para eu e o meio, onde estou inserido, como posso contribuir para a melhoria dos ambientes que eu frequento e assim por diante. $(P-14)$.
\end{abstract}

A proposta apresentada pelos professores vai ao encontro dos pressupostos e direcionamentos presentes no Caderno de Educação Integral da Rede Municipal de Curitiba, para as práticas em Educação Ambiental. O documento, indica que:

A Educação Integral entende o ser humano em todas as suas dimensões,
considerando que o conhecimento é construído tanto no campo da razão
como no da emoção, sendo a afetividade componente essencial desse
processo. Na direção dessa formação humana, é fundamental que os
ambientes escolares sejam reorganizados, otimizados e ampliados em
termos de tempos e espaços, nos quais sejam desenvolvidas atividades
pedagógicas complementares às que se verificam no cotidiano escolar
regular. Ampliar o espaço significa ampliar o olhar sobre o espaço físico
também, e o professor pode conduzir seu estudante a percorrer o caminho
até a escola observando, fotografando e relatando por escrito as diversas
observações sobre esse espaço. O professor deve reorganizar os objetivos a 


\section{THsm

ISSN: 1984-6444 | http://dx.doi.org/10.5902/1984644433540

Deveria ser matéria obrigatória em uma escola, já que visa à base para o ser humano, ao contrário de matemática e português a ed. ambiental ensina com ser um bom cidadão a tomar atitudes corretas ao contrário do que muitos pensam educação. Ambiental não é só reciclar e cuidar do meio ambiente é ter um mundo melhor para se viver, desde separar o lixo a ser solidário com o próximo. $(P-6)$.

De acordo com Loureiro, Layrargues e Castro (2009, p. 27), a "Educação Ambiental é educação e, como tal, serve ou não para manter ou mudar a realidade, reproduzir ou transformar a sociedade. A educação 'ambiental' não só poderia como deveria ser praticada com compromisso social".

Há, no entanto, uma dificuldade evidente no que tange à questão de contemplar e compreender a relação entre o ambiental e o social. A dificuldade em realizar o vínculo entre estas duas questões, está evidenciada nos argumentos de muitos dos participantes desta pesquisa.

Loureiro, Layrargues e Castro $(2009$, p.26) ressaltam que, "a dificuldade de perceber o vínculo entre a questão ambiental e social é devida a uma questão de entendimento: desde que se cunhou o termo educação ambiental, o adjetivo 'ambiental' foi predominantemente compreendido como sinônimo de 'ecológico'". Ainda que desde 1977 se ressalte que a Educação Ambiental não é sinônimo de educação ecológica, esta ideia ainda prevalece em muitos discursos.

$\mathrm{Na}$ segunda etapa da pesquisa, foram formuladas três frases afirmativas sobre a prática pedagógica, para que os participantes apontassem seu nível de conformidade e, assim, reafirmassem as ideias presentes na primeira rodada de perguntas abertas, sob as seguintes variáveis: E- Extremamente; $M$ - Muito; R Razoável; P - Pouco; N - Nenhum; NSA - Não se aplica. Os resultados estão indicados na tabela 3. 


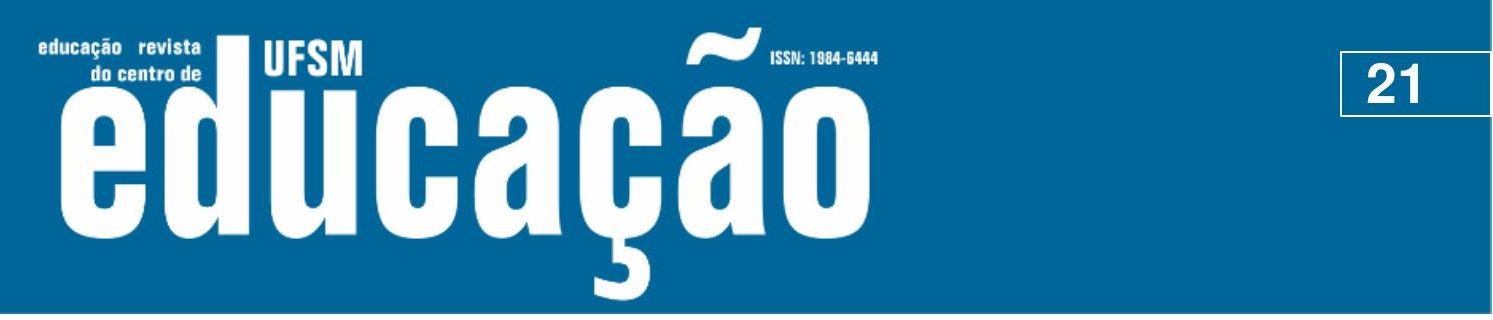

ISSN: 1984-6444 | http://dx.doi.org/10.5902/1984644433540

sim deve promover uma tomada de consciência sobre nossa interferência no meio ambiente.

A questão 2, ressaltada com 56,6\%, sob a variável "Muito", apresenta-se como uma percepção conservacionista/recursista que, segundo Sauvé (2005, p. 19 e 20), tem relação com a gestão ambiental, ou seja, administração do meio ambiente:

[...] centrando-se na conservação de recurso, centrada na 'conservação' dos recursos, tanto no que concerne à sua qualidade quanto à sua quantidade: água, o solo, a energia, as plantas (principalmente plantas comestíveis e medicinais) e os animais (pelos recursos que podem ser obtidos deles), [...] quando se fala de 'conservação da natureza', como biodiversidade, trata-se, sobretudo de uma natureza-recurso.

É ressaltado também nesta corrente "a educação para o consumo, além de uma perspectiva econômica, integrou mais uma preocupação ambiental da conservação de recursos, associada a uma preocupação de equidade social" (SAUVÉ 2005, p. 20).

Tais características foram reafirmadas com $33,3 \%$, na questão complementar e suas justificativas foram as seguintes:

Procuro repassar aos alunos que tudo o que precisamos para nossa sobrevivência encontramos nos recursos naturais, por isso devemos zelar e usar com responsabilidade, pois o desperdício pode levar a escassez e extinção da humanidade. (P-2).

Conscientizar que os recursos naturais são esgotáveis e se não forem utilizados de maneira sustentável podem vir a faltar. $(P-3)$

Para que possamos viver com mais qualidade, deixando um mundo melhor para futuras gerações, criando um novo hábito da preservação, uma nova cultura e lutando por um equilíbrio entre o ser humano e a natureza. $(P-7)$.

Sanchs, faz uma advertência sobre a linha recursista:

Que luzes projetamos sobre as coisas (ou sobre os seres humanos) que em seguida elas são qualificadas de recursos? Aparentemente, atribui-se a elas importância porque são uteis para fins superiores. O que conta não é o que elas são, mas o que elas podem vir a ser. Um recurso é uma coisa que não cumpre seu fim senão quando é transformada em outra coisa: seu valor próprio se volatiliza ante a pretensão de interesses superiores. (...) Nossa percepção esteve acostumada a ver a madeira de construção numa mata, o mineral numa rocha, os bens de raiz numa paisagem e o portador de qualificações num ser humano. O que se chama recurso está situado sob jurisdição da produção (...). Conceber a água, o solo, os animais ou os seres humanos como recursos os marca como objetos que necessitam da gestão de planejadores e o cálculo de preços dos economistas. Este discurso ecológico leva a acelerar a famosa colonização do mundo vivo. (SANCHS, 2000, p. 77-78 apud SAUVÉ, 2005, p. 21) 


\section{Fism

ISSN: 1984-6444 | http://dx.doi.org/10.5902/1984644433540

De acordo com Saheb (2008, p. 23), "à medida que a humanidade amplia a sua capacidade de intervenção na natureza em prol da satisfação de suas necessidades e desejos crescentes, intensificam-se as tensões e conflitos em relação à utilização do espaço e à intensa exploração dos recursos naturais".

A ideia reducionista que contempla a natureza como servível ao homem coloca o ser humano dissociado da natureza, assumindo uma postura de superioridade diante do ambiente. Em vista disso, é necessário ressaltar a importância de não considerar a natureza como um mero recurso natural passível de usufruto humano, mas sim como parte do todo que constitui as partes.

\section{Considerações Finais}

A questão ambiental impõe à sociedade novas formas de pensar e agir para suprir as necessidades humanas e, ao mesmo tempo, garantir a sustentabilidade ecológica. Para isso, é necessário conhecer as representações dos professores em relação ao meio ambiente, pois a esfera educacional assume um papel primordial, no que respeita à perspectiva ambiental, dado que a escola pode ser vista como modelo de boas práticas.

É importante que os educadores privilegiem em suas práticas a superação da fragmentação do ensino, possibilitando às crianças uma reflexão sobre as relações estabelecidas com a natureza, para além do âmbito educativo, o que significa trabalhar tais relações contemplando o âmbito social como parte indissociável do meio ambiente.

Por meio da análise apresentada, ficou patente que a Educação Ambiental, ainda que proposta como um eixo interdisciplinar nos documentos que a respaldam, não está sendo trabalhada à luz desse pressuposto. De acordo com Saheb (2008, p.29), "a interdisciplinaridade pressupõe o diálogo e o planejamento cooperativo entre as diferentes disciplinas", no entanto, foi possível identificar práticas dissociadas, superficiais e fragmentadas como as demais disciplinas, ainda que não seja considerada como tal. 


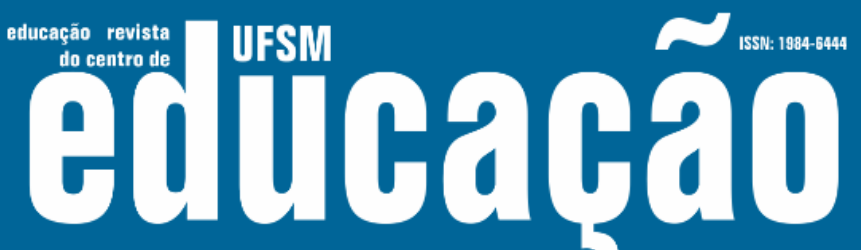

ISSN: 1984-6444 | http://dx.doi.org/10.5902/1984644433540

Foi possível compreender que a formação de atitudes de reflexão é essencial para garantir o sucesso da Educação Ambiental no âmbito educacional, para que, assim, o professor (a) possa compreender e identificar os conhecimentos necessários à formação de atitudes voltadas à temática ambiental.

Some-se a isso, a necessidade de dotar os professores de mais subsídios teóricos e metodológicos, para que possam promover aprendizagens mais significativas por meio das práticas em Educação Ambiental, apontando, assim, a relevância de trabalharem com os problemas locais, além de permitir um envolvimento maior deles nessas questões, trazendo reflexões imprescindíveis para a problemática ambiental, sendo elas, culturais, sociais, econômicas, políticas e históricas.

Outro aspecto evidenciado foi, a coexistência entre concepções que se encaminham para uma abordagem crítica de Educação Ambiental e a predominância de concepções voltadas a uma visão reducionista que considera a Educação Ambiental como educação para preservação e conservação de recursos naturais, dissociando os aspectos sociais dos ambientais.

A relevância deste estudo é reafirmada com o fato de a Educação Ambiental estar a cargo de um docente responsável por essa prática nas escolas integrais da rede municipal de Curitiba, PR. Os dados obtidos permitiram a compreensão de características importantes do pensamento e da ação desses professores.

Uma alternativa para sanar as carências encontradas seria um processo de formação continuada voltada à temática ambiental, que vá além de uma mera atualização científica ou pedagógica e se constitua como um espaço que possibilite discussões e reflexões, com uma proposta vinculada à formação de cidadãos críticos, capazes de construir conhecimentos mediante a mudança de valores e adoção de uma postura ética e crítica perante as questões ambientais, deixando de serem meros ouvintes, para serem profissionais participativos e reflexivos. 


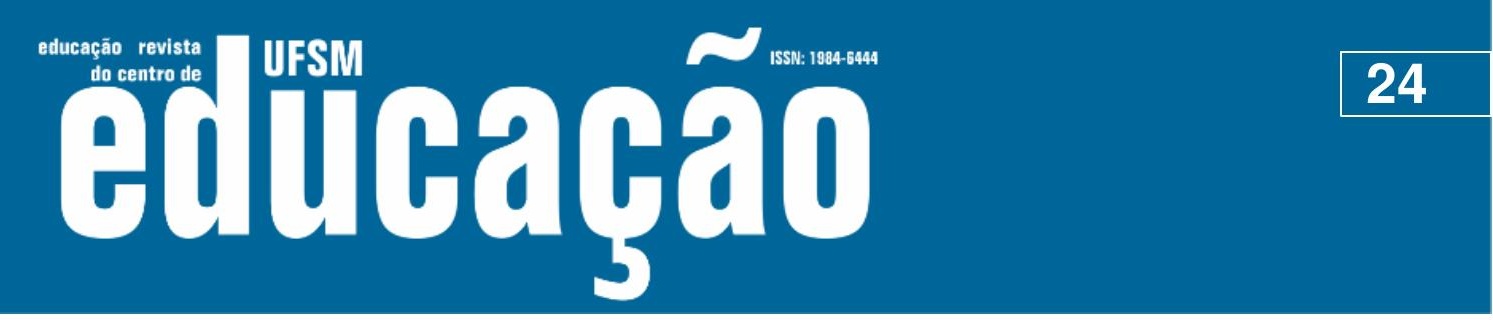

ISSN: 1984-6444 | http://dx.doi.org/10.5902/1984644433540

\section{Referências}

ANTUNES, Marcelo Moreira. Técnica Delphi: metodologia para pesquisas em educação no Brasil. Revista de Educação PUC-Campinas, Campinas, v. 19, n. 1, p. 63-71, jan./abr., 2014. Disponível em: http://periodicos.puccampinas.edu.br/seer/index.php/reveducacao/article/view/2616/1894. Acesso em: 25 out. 2017

BEHRENS, Marilda Aparecida; ENS, Romilda Teodora. Complexidade e Transdisciplinaridade: Novas perspectivas teóricas e práticas para a formação de professores. 1.ed. Curitiba, Appris, 2015.

BRASIL. Resolução CNE n. 2, de 7 abril de 1998. Institui as Diretrizes Curriculares Nacionais para o Ensino Fundamental. Brasília: MEC, 1998. Disponível em: http://portal.mec.gov.br/dmdocuments/resolucao_ceb_0298.pdf. Acesso em: 22 abr. 2017.

BRASIL. Resolução CNE/CP no 2, de 15 de junho de 2012. Estabelece as diretrizes curriculares nacionais para a educação ambiental. Brasília: MEC, 2012. Disponível em:

http://portal.mec.gov.br/index.php?option=com_docman\&view=download\&alias=1098 8-rcp002-12-pdf\&category_slug=maio-2012-pdf\&Itemid=30192. Acesso em: 22 abr. 2017.

BRASIL. Série Cadernos pedagógicos. Educação Ambiental. Programa Mais Educação. Brasília: MEC, [2010?]. Disponível em: http://educacaointegral.mec.gov.br/images/pdf/pme/educacao_ambiental.pdf. Acesso em: 07 set. 2017.

BRASIL. Série Mais Educação: Educação Integral. Texto referencial para o debate nacional. Brasília: MEC, 2009. Disponível em: http://educacaointegral.mec.gov.br/images/pdf/bibioteca/ cadfinal_educ_integral.pdf. Acesso em: 07 set. 2017.

CARVALHO, Isabel Cristina de Moura. Educação Ambiental: a formação do sujeito ecológico. 6. ed. São Paulo: Cortez, 2012.

CURITIBA. Caderno Pedagógico de Educação Integral. Curitiba: SME, 2012. Disponível em: http://multimidia.educacao.curitiba.pr.gov.br/2017/4/pdf/00131553.pdf Acesso em: 07 set. 2017.

GUIMARÃES, Mauro. A formação de educadores ambientais. 8. ed. Campinas, São Paulo: Papirus, 2014.

IMBERNÓN, Francisco. Formação Docente e Profissional: formar-se para a mudança e a incertezas. Tradução Silvana Cobucci Leite. 9. ed. São Paulo: Cortez, 2011. 


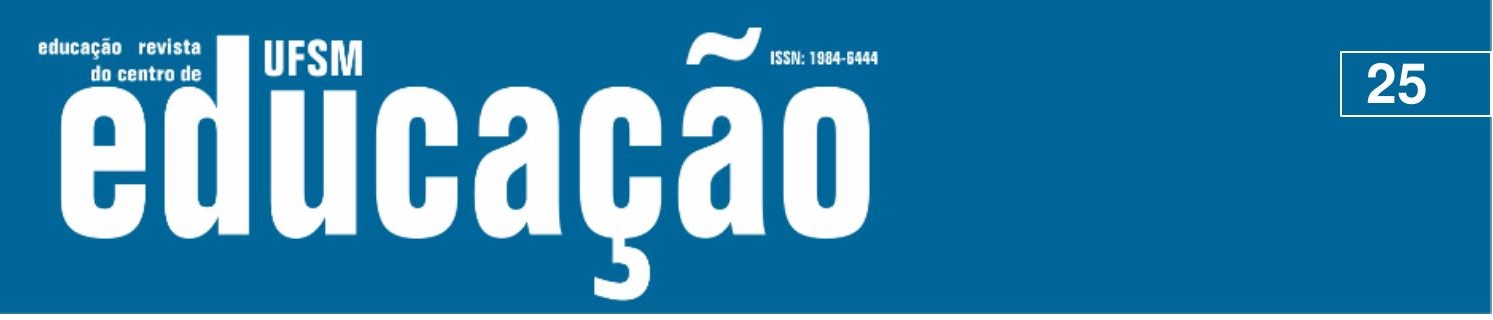

ISSN: 1984-6444 | http://dx.doi.org/10.5902/1984644433540

LAKATOS, Maria Eva; MARCONI, Marina de Andrade. Metodologia do trabalho científico: procedimentos básicos, pesquisa bibliográfica, projeto e relatório, publicações e trabalhos científicos. São Paulo: Atlas, 2012.

LEFF, Enrique. A complexidade ambiental. Trad. Eliete Wolff. 2. ed. São Paulo: Cortez, 2010.

LEFF, Enrique. Saber Ambiental: sustentabilidade racionalidade, complexidade, poder. Trad. Lúcia Mathilde Endlich Orth. 11. ed. Petrópolis, RJ: Vozes, 2015.

LOUREIRO, Carlos Frederico Bernardo; LAYRARGUES, Philipe Pomier; CASTRO, Ronaldo Souza. Repensar a educação ambiental: um olhar crítico. São Paulo: Cortez, 2009.

MINAYO, Maria Cecília de Souza. O desafio do conhecimento: pesquisa qualitativa em saúde. 14. ed. São Paulo: Huricitec, 2014.

MORALES, Angélica Góis. A Formação do Profissional educador ambiental: reflexões, possibilidades e constatações/ Angélica Góis Morales. Ponta Grossa: ed. UEPG, 2009. 203p

PACIEVITCH, Thais. Interculturalidade na educação em direitos humanos: uma perspectiva emancipatória. 2016. 129 f. Tese (doutorado) - Pontifícia Universidade Católica do Paraná, Curitiba, 2016. Disponível em: http://www.biblioteca.pucpr.br/pergamum/biblioteca/img.php?arquivo=/00005c/00005 cd5.pdf. Acesso em 13 abr. 2017.

SAHEB, Daniele. A educação socioambiental e a formação em Pedagogia. 2008. 113f. Dissertação (mestrado). Programa de Pós-Graduação em Educação. Universidade Federal do Paraná. Curitiba, 2008. Disponível em: http://www.ppge.ufpr.br/teses/M08_saheb.pdf. Acesso em: 25 out. 2015.

SAHEB, Daniele. Os saberes socioambientais necessários à educação do presente e a formação do educador ambiental sob o foco da Complexidade. 2013. 228 f. Tese (doutorado) - Universidade Federal do Paraná, Curitiba, 2013. Disponível em: http://acervodigital.ufpr.br/bitstream/handle/1884/36381/R\%2020T\%20\%20DANIELE\%20 SAHEB.pdf?sequence=1\&isAllowed=y. Acesso em: 22 abr. 2017.

SAHEB, Daniele. RODRIGUES, Daniela Gureski. A Educação Ambiental na Educação Infantil: Limites e Possibilidades. Cad. Pes., São Luís, v.23, n 1, jan./abr. 2016.

SAUVÉ, Lucie. Uma cartografia das correntes em Educação Ambienta. In: SATO, Michele; CARVALHO, Isabel (orgs.). Educação Ambiental: pesquisa e desafios. Porto Alegre: Artmed, 2005. p. 17-45.

SOUZA, Regina Aparecida Machado. Educação Ambiental e Cidadania. In: HAMMES, Valéria Sucena; RACHWAL, Marcos Fernando Gluck. Meio ambiente e a escola. Brasília, DF: Embrapa, 2012. p. 43-61. 


\section{ussm \\ 15SN: 1984-6444

ISSN: 1984-6444 | http://dx.doi.org/10.5902/1984644433540

TORALES, Marília Andrade. A práxis da Educação Ambiental como processo de decisão pedagógica: um estudo biográfico com professoras de educação infantil na Galiza (Espanha) e no Rio Grande do Sul (Brasil).2006. 566f. Tese (Doutorado Interuniversitário em Educação Ambiental). Universidade de Santiago de Compostela, Espanha, 2006.2 Disponível em: https://minerva.usc.es/xmlui/bitstream/handle/10347/9496/b20101545.pdf;jsessionid= C7515A62A165F66230B2DA5928D6112B? sequence=1. Acesso em: 25 out. 2017.

\section{Correspondência}

Chrizian Karoline Oliveira - Pontifícia Universidade Católica do Paraná - R. Imac. Conceição, 1155, CEP 80215-901, Prado Velho, Curitiba, Paraná, Brasil.

\section{(c) ${ }_{\mathrm{EY}}($ )}

This work is licensed under a Creative Commons Attribution-NonCommercial 4.0 International (CC BY-NC 4.0) 